Electronic version of an article published as Shahzad, Muhammad Usman, Davis, Kate and Ahmad, Muhammad Shakil (2021) Knowledge oriented leadership and open innovation : the mediating role of knowledge process and infrastructure capability. International Journal of Innovation Management (IJIM), 25(3), p. 2150028.

https://doi.org/10.1142/s1363919621500286

(C) copyright World Scientific Publishing Company

https://www.worldscientific.com/doi/abs/10.1142/S1363919621500286 
Knowledge Oriented Leadership and Open Innovation: The Mediating Role of Knowledge Process and Infrastructure Capability

Mr. Shahzad Usman

Department of Management Sciences, COMSATS University Islamabad, Attock Campus, Attock, 43600, Pakistan

Email: md38298@gmail.com

\section{Dr Kate Davis}

Senior Lecturer of Department of Accounting, Finance and Informatics

Kingston Business School, Kingston University

Email:kate.davis@kingston.ac.uk

\section{Dr Muhammad Shakil Ahmad}

Department of Management Sciences, COMSATS University Islamabad, Attock Campus, Attock, 43600, Pakistan

Email: onlyshakl@gmail.com 


\title{
Knowledge Oriented Leadership and Open Innovation: The Mediating Role of Knowledge Process and Infrastructure Capability
}

\begin{abstract}
Purpose- The study aims to examine the causal relationships among knowledge-orientedleadership (KOL), open innovation (OI), knowledge infrastructure capability (KIC) and knowledge process capability (KPC). This study also explored the mediating role of knowledge infrastructure capability (KIC) and knowledge process capability (KPC) in the relationship between knowledge oriented leadership and open innovation.

Design/methodology/approach - The study collected primary data via a standardized questionnaire comprising a sample of 305 Pharmaceutical and Health sector employees in Pakistan. Hypotheses were tested through structural equation modeling.

Findings - The results display the significant causal relationships among the variables and knowledge infrastructure and process capability and these significantly mediate the relationship between knowledge-oriented-leadership and two-dimensional open innovation. Furthermore, this study found an insignificant effect of KOL on inbound open innovation.

Limitation - the findings of the present research are based on the data collected from the Pakistan pharmaceutical and health sector. In future to accommodate the issue of generalizability, the framework can be used for samples from other countries.

Practical Implication -This study provides evidence that leadership is one of the most crucial sources that can aid in organizational effectiveness when dealing with knowledge by developing infrastructure and improving processes to enhance innovative outcomes.
\end{abstract}

Keywords - Knowledge oriented leadership; open innovation; Outbound open innovation; Knowledge infrastructure capability; Knowledge process capability 


\section{Introduction}

Open Innovation (OI) is a strategic source that helps to improve and facilitate organizational competitiveness to further develop market leader capabilities (Ades et al., 2013; Han et al., 2012; Ili, Albers, \& Miller, 2010; Kodama \& Shibata, 2015). Over the past decade, OI has been extensively discussed in management of innovation literature (e.g., Chesbrough, 2003; Dahlander \& Gann, 2010; Enkel, Gassmann, \& Chesbrough, 2009; Lichtenthaler, 2009; West $\&$ Gallagher, 2006) and, as a consequence, the complexities associated with innovation have amplified due to the increased amount of knowledge available to organizations(Du Plessis, 2007; Giudice \& Maggioni, 2014). (Chesbrough \& Bogers, 2014), "explained OI as a disseminated innovation development based on purposively managed knowledge flows across firm's boundaries, in which OI is essentially a concept that resides at the level of the organization". OI shows that innovation outcomes can be enhanced by both obtaining knowledge from outside the organization and through exploitation of a firm's knowledge through commercialization in the external market (Bigliardi \& Galati, 2018; Galati, Bigliardi, \& Petroni, 2016; Greco, Grimaldi \& Cricelli, 2019; Oltra, Flor, \& Alfaro, 2018; Usman \& Vanhaverbeke, 2017).

Innovation outcomes are usually indicated by numerous accomplishments (e.g. the product is continuously updated to meet new market technology, innovative production process, and exploitation of new markets) (Hung, Lien, Yang, Wu, \& Kuo, 2011).Furthermore, Dahlander \& Gann(2010) highlighted that as the emergence of OI models challenge organizations to change their traditional innovation paradigms, firms would be required to follow more modernday approaches to innovation management. Hence, moving to contemporary processes of innovation invite organizations to make a corresponding move in their leadership models from customary to modern (Robbins \& O'Gorman, 2015). The principle of OI and its effectiveness to foster organizational innovation is well appreciated in the literature. However, in knowledgeoriented cultures, when organizations face difficulties in offering new products and services over effective usage of sources accessible to them(Vaccaro, Jansen, Van Den Bosch, \& Volberda, 2012) then knowledge oriented leadership is a source which helps them to deal with challenges by improving knowledge-management (KM) capability(Naqshbandi \& Jasimuddin, 2018). Furthermore, organizations use knowledge as a strategic source, whereby they generate value by discovering and manipulating it through its appropriate management and achievement of competitive advantage (Bigliardi, Galati, \&Petroni, 2014; Bolisani \& Bratianu, 2017; Dezi, 2017; Hansen, Nohria, \& Tierney, 1999; Jasimuddin, 2008; Loebbecke, van Fenema, \& Powell, 2016). The proper management of knowledge impacts organizational innovation as it influences the organizational hierarchy, leadership, procedures, and values that facilitate innovation (Elenkov \& Manev, 2005). Leadership has moved from the industrial age towards the knowledge era (Uhl-Bien, Marion, \& McKelvey, 2007). As a result, KOL becomes an essential element in organizations to deal with OI (Naqshbandi \& Jasimuddin, 2018). For the organization, knowledge-processes capability and knowledge-infrastructure-capabilities are basic requirements for managers to improve OI results in the organization. However, limited research has examined the role of mediating apparatus through which knowledge-oriented 
leadership influence two-dimensional OI (inbound and outbound) outcomes. This research addresses this study gap.

The aim of this study is to investigate the causal relationship among knowledge-orientedleadership (KOL), knowledge infrastructure capability (KPC), knowledge process capability (KPC) and OI (inbound and outbound OI) and the mediating role of KIC and KPC between KOL and OI. (Donate \& de Pablo, 2015) were pioneers to KOL and KM theory by offering a framework that defines how KOL enhances innovation outcomes through KM practices. Similarly, (Naqshbandi \& Jasimuddin, 2018) examined the relationship among KOL, and OI. They believe that studies which explore the significance of KOL and OI are limited. This study provides empirical evidence, based on large sample size, investigating how KOL plays important role in enhancing OI outcomes.

Secondly, this study examines the role of KIC and KPC as a separate mediator between KOL and OI (inbound and outbound). According to Naqshbandi \& Jasimuddin, (2018), to confirm the significant use of knowledge sources, organizations need to have an infrastructure that contains technological, structural and an encouraging organizational culture. Moreover, numerous studies have explored that organizations with healthier KIC outclass their opponents in terms of innovative results (Donate \& de Pablo, 2015; Naqshbandi \& Jasimuddin, 2018). On the other hand, Lin\& Lee (2005) argue that to ensure the best usage of KM resources, organizations are required to have a well balance process management system, such as acquisition, sharing and application of knowledge. Several studies have examined the supportive role of the system in organizations which encourage innovative knowledge formation, division and how execution plays a vital role in the improvement of innovative outcomes (Darroch, 2005; Donate \& de Pablo, 2015; Naqshbandi \& Jasimuddin, 2018). (Naqshbandi \& Jasimuddin, 2018) examined the mediating role of KM capability between KOL and OI, but research about the mechanism that conveys the impact of KOL on OI is limited. Notably, little is known about the mediating role of KIC and KPC regarding KOL and OI. This study addresses this research gap.

In contrast to this setting, this study will focus on KOL for the development of KIC and KPC for OI purposes in pharmaceutical and health departments of Pakistan. This study suggests the intervening role of $\mathrm{KIC}$ and $\mathrm{KPC}$, by arguing that leaders are liable for increasing KIC by developing culture, structures and application of technology that encourage creation and utilization of knowledge (Naqshbandi \& Jasimuddin, 2018). Alternatively, leaders are also responsible for KPC by improving acquisition, sharing, and application of knowledge processes of an organization(Lin \& Lee, 2005; Lin \& Huang, 2008).

The aim of this paper is to address the following research question; how can organizations achieve innovation objectives by establishing a knowledge infrastructure and KPC through KOL? Four main objectives are addressed: (1) To analyze the relationship between KOL and OI (i.e. inbound and outbound OI); (2)to investigate the causal relationship among KOL, KPC, KIC and OI (inbound and outbound OI); (3) To explore the mediating role of KPC (i.e. acquisition, sharing, application) in the relationship among KOL and open-innovation; (4) to examine the mediating effect of KIC (i.e. cultural, structural and technological infrastructure) in the relationship between KOL and OI. 


\section{Literature Review}

\section{Theoretical background}

According to knowledge based theory of the firm, basic knowledge creation, its integration and application is considered as an essential function of an organization (Grant, 1996; Kogut \& Zander, 1992). This theory is rooted in the resource-based perspective of an organization (Donate \& de Pablo, 2015; Shamim, Cang, \& Yu, 2017), which includes strategic resources as a key factor for organizational competitiveness. In the knowledge based view, organizations consider knowledge as a key strategic source which enables them to create value in the market (Lauri, Heidmets, \& Virkus, 2016). The issue of numerous organizations struggling for competitive advantage is that they exert increased effort in identifying knowledge rather than understanding how to produce, maintain and share knowledge. Consequently, it is essential for organizations to establish and execute exercises that can help them convey their capacities for competitive advantage.

In addition, Vlasveld, Fischer, Swierenga, \& Picken (2008) operationalize the KPC of an organization as the process of knowledge acquisition, sharing, application, and protection of knowledge. Grant (1996) categorized knowledge in two groups; explorative and exploitative. Explorative practices involve knowledge creation that refers to creating new knowledge. Exploitative practices include knowledge storage, knowledge sharing and application. Knowledge acquisition refers to acquiring new knowledge that can be replaced with the organization's existing knowledge. Darroch \& McNaughton (2002) state that knowledge creation activities are closely linked to the firm's internally developed knowledge, such as research and development. During the knowledge creation process organizations may lose or forget some of their acquired knowledge (Alavi\& Leidner, 2001; Alavi, 2001) and therefore organizations must store their acquired knowledge.

According to Grant (1996) a series of activities and initiatives must be developed and implemented by organizations which help them to establish their organizational KM capability (KPC and KIC). A main objective of an organization is to convert and use the obtained Naqshbandi \& Jasimuddin (2018) knowledge to get the most out of it to attain competitive advantage (Donate \& de Pablo, 2015) point out that for the improvement of OI outcomes, KM capability (KIC and KPC) of an organization are key sources in several sectors including the pharmaceutical industry. These organization sectors should work on increasing KM to meet the requirements of client beliefs, maintain their satisfaction and loyalty, and increase service quality. For example, establishing the role of KM capability (KIC and KPC) can facilitate innovation outcome of an organization (Donate \& de Pablo, 2015; Naqshbandi \& Jasimuddin, 2018).

Nevertheless, in health and pharmaceutical sectors where competitiveness depends on the capability of an organization to continually establish innovative products or processes; the most essential challenge for KM is seems to be OI (Raisch\& Birkinshaw, 2008; Subramaniam $\&$ Youndt, 2005). The present study concentrates on OI (inbound and outbound) as one of KM 
essential requirements for firms in terms of organizational competitiveness. The further discussion will explain the relationship among KOL, OI (inbound and outbound), and their relationship with KPC and KIC. Figure-1 shows the research model of the study.

H6 \& H7

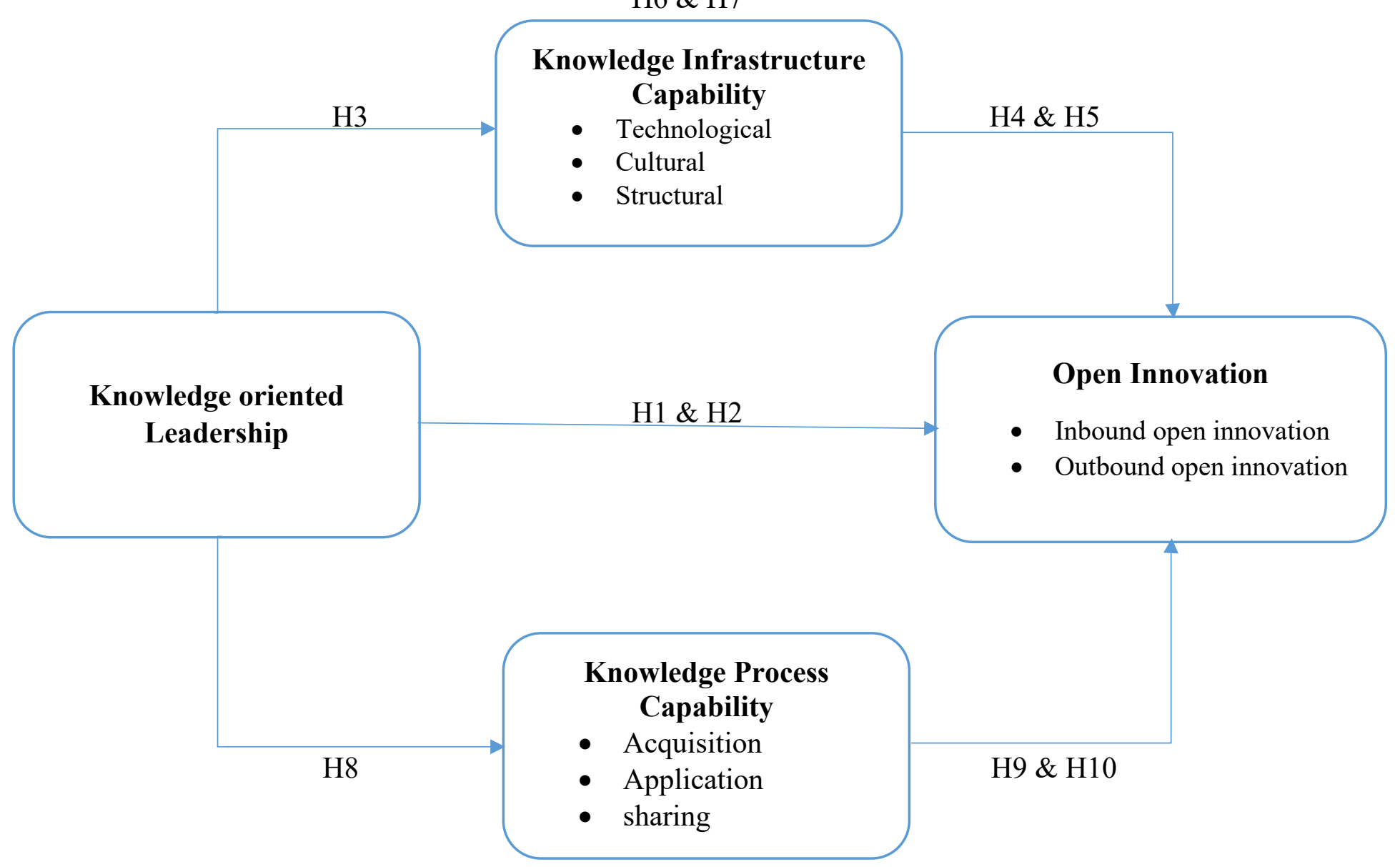

H11 \& H12

Figure-1: Research Model

\section{Knowledge-oriented-leadership}

KOL is a mutual or individual act which evaluates, improves and executes a new approach of thinking and achieves collective results in the organization (Mehmood \& Hussain, 2017). For this study, KOL is an approach or act, noticed or imputed, that energizing the formation, distribution, and operationalization of innovative knowledge in a means that looks to carry a change in thinking and shared results. Numerous researchers have highlighted that leadership is a main contributor for inspiring followers into complying with decisions taken by leaders (Shamim et al., 2017). Few others have highlighted the job of leadership in producing, obtaining, converting and applying knowledge, revealing numerous roles such as mentors, promoters, facilitators and motivators (Vaccaro et al., 2012; Yang, 2007).This study will follow the KOL style which was presented by Donate\& de Pablo (2015), which is based on the 
combination of the transactional and transformational leadership styles adjacent to motivation and communication elements.

$\mathrm{KOL}$ is described as the procedure by which each group member facilitating the learning cycle are required to achieve the objectives of the organization. This also may help in developing mechanisms that exchange and control the sharing of knowledge with customers (Mohsenabad \& Azadehdel, 2016). Several scholars have stated that KOL plays key role in increasing organizational knowledge, organizing, managing knowledge and creating insight (Donate \& de Pablo, 2015; Lakshman \& Parente, 2008; Mohsenabad \& Azadehdel, 2016). In addition, several studies have acknowledged the role of KOL in sourcing, creating, sharing, transforming and using organizational knowledge, as well as noting various functions e.g. promoters, initiators and role model(Donate \& de Pablo, 2015; Naqshbandi \& Jasimuddin, 2018). Furthermore, a knowledge oriented leader appreciates learning, helps in training, with emphases on knowledgeable encouragement of employees and provides incentives to establish the system for sharing, storing and applying organizational knowledge (Williams \& Sullivan, 2011). Yahya \& Goh (2002) note that leadership and organizations should establish the culture inside the organizations where KM practices can appropriately manage knowledge. In this manner, Wang \& Ahmed (2007) and Zollo \& Winter (2002) state that knowledge-based management becomes the forceful capability of association, which boosts formation, distribution and application of knowledge in the organization.

Several studies have recognized that leader-ship is a crucial factor in efficiently dealing with organizational knowledge (Kant \& Singh, 2009; Singh \& Kant, 2008). In view of (J. Te Yang, 2010) the mentoring, facilitating, and innovating attitude of leaders also a have significant impact on creating and maintaining KM behavior. Furthermore, the leader-ship of an organization should guide to their Knowledge oriented workers to learn and utilize knowledge, in this manner they can achieve their organizational innovative objectives and individual as well (Ribière\& Sitar, 2003). KOL indicates affording KM and important role in the organization to sense and grab opportunities to innovate. In this viewpoint, knowledge-oriented leaders must champion the advancement of KM means and initiatives for either knowledge exploitation or knowledge exploration. In detail, Best KM practices must be promoted by effective KOL style, motivation, communication and staffing as well (Donate \& de Pablo, 2015).

\section{Open Innovation}

OI is a strategic source that helps improve and facilitate organizational competitiveness to further develop market leader capabilities. The concept of innovation was presented by Schumpeter (1934); he described open innovation in five ways, up to date product, innovative production processes, new resources for supply, the opening of a new market and the creation and application of a new organization structure in an industrial sector. The OI concept depends on the knowledge flow directions (inside and outside) and importance of openness level for the organizations (Chesbrough, 2010; Žemaitis, 2014). Chesbrough (2003)classified open innovation into two types; inbound open innovation and; outbound open innovation. 


\section{Inbound and outbound Open Innovation}

Inbound OI includes distinguishing and obtaining knowledge from outside the organization. The inbound OI approach pushes organizations to discover how to search for potential sources of precious knowledge or technology (Eckhardt, Ciuchta, \& Carpenter, 2018; Greco et al., 2019). Likewise, an inbound OI approach on behalf of big companies creates innovative opportunities that encompass the front-end of innovation (e.g. OI strategies of big pharmaceutical firms generate chances for biotech innovative ventures) (Bogers et al., 2017; Lopez-Vega, Tell, \&Vanhaverbeke, 2016). Accordingly, accessible ideas are cautiously analyzed, distinguished, selected and obtained by the organization that they view as complementary to their plans of action (Chesbrough, 2003). Inbound OI involves inner technology transfer, which further defines the practices of benefitting from the discoveries of others, since organization requirements depend on their own research and development (Chesbrough \& Crowther, 2006). Furthermore, it refers to organizations opening and improving relations with external organizations to capture their capabilities to improve organization innovation outcome. Naqshbandi, Garib Singh, \& Ma (2016) state that this type of innovation implies purposive acquisition of technology or knowledge relevant with innovation activities that aim at seizing and leveraging from outer resources to advance existing technical growths.

Outbound OI refers to organizational knowledge, ideas or technology that can be commercialized in the external market for better exploitation (Chesbrough, 2003). The joined process indicates that organizations collaborate with other firms in strategic networks by coupling the outside-in and inside-out processes, in order to integrate external ideas and capabilities and expressing the own ones (Bigliardi \& Galati, 2016). Lichtenthaler (2009) asserts that outbound OI emphasizes the active encouragement of external knowledge exploitation and discusses its commercialization using licensing and other allocation resources. Furthermore, outbound OI recommends not depending on interior paths to market but looking for the other means with which business paradigms are best suited for the commercialization of a certain technology (Chesbrough \& Crowther, 2006; Brunswicker and Chesbrough, 2018). This sort of commercialization depends on the organization's internal competencies and its connections with outer sources (Dahlander \& Gann, 2010).

\section{Knowledge Infrastructure Capability}

Several studies have recognized the importance of knowledge infrastructure to underpin an organization's KM initiatives (Donate \& de Pablo, 2015; Naqshbandi \& Jasimuddin, 2018). Usually, the KIP of an organization is made up of three elements and in this research the typology of KIP has been adopted from the study of Gold, Malhotra, \& Segars (2001), which is based on technological, structural and cultural infrastructure capability. Firstly, the technological capability of an organization contains the information and technology system that facilitates the combination of knowledge and information in the firm, along with the creation, handover, storage, and protection of the different knowledge means (Davenport, De Long, \& Beers, 1998. Secondly, the structural capability involves the rules and regulations, norms, reporting system and organizational hierarchy level, and is considered a source of coordination and hold through which organizational factors can be directed in the direction of 
organizational efficacy (Gold et al., 2001). Lastly, the cultural infrastructure capability is defined as ethics, beliefs, behavioral structure, and symbols that depict an organization's values (Gold et al., 2001).

\section{Knowledge Process Capacity}

To ensure the best usage of knowledge, organizations are required to have a well-balanced process management system such as acquisition, sharing and application of knowledge and its sharing (Nonaka \& Takeuchi, 1995). Furthermore, acquisition of knowledge includes an organization's competency to categorize, procure and gather knowledge (whether inside or outside the organization) which is crucial to its processes (Gold et al., 2001; Zahra \& George, 2002). Further, application of knowledge refers to building knowledge more effectively and appropriately for the organization in enhancing its worth, and to create value by utilizing this knowledge for services and products by different means, e.g. repackaging available knowledge, training and motivating its people to think creatively, utilizing people's understanding of the company's processes, products and services(Bhatt, 2001). Knowledge sharing is explained as the KM processes that allocate knowledge among all entities contributing to process activities. The literature on KM capability emphasizes that a knowledge sharing culture is a core organizational condition for successful $\mathrm{KM}$ and leverage mentation (Damodaran \& Olphert, 2000).

\section{Knowledge-Oriented-Leadership and In-bound OI}

Several studies explore leadership as a significant element when dealing with organizational knowledge (Donate \& de Pablo, 2015; Kant \& Singh, 2009; Naqshbandi \& Jasimuddin, 2018). Leadership is particularly associated with knowledge when subordinates see management as effectively focusing and engaging on supporting learning and knowledge based exercises (DeTienne, Dyer, Hoopes, \& Harris, 2004). As mentioned above, in-bound OI refers to the organization analyzing, identifying, obtaining and integrating knowledge into their interior mechanisms and processes. For this purpose, organizations require capable leaders with suitable skills to asses and determine what kind of knowledge sources should be acquired in order to efficiently meet the organization's innovative plan of action (Dahlander\& Gann, 2010).

To efficiently obtain and combine knowledge from outside resources, organization's depend on leaders who appreciate knowledge practices that back the improvement of knowledge and its acquirement (DeTienne et al., 2004). Specifically, KOL integrates transactional and transformational leadership styles (Donate \& de Pablo, 2015) and validates knowledge by producing, distributing, storing and implementing it. One of the most significant roles that leadership plays is to encourage and influence employees to attain organization's objectives in improving innovation results (Ribière\& Sitar, 2017). Hence, developing an environment through KOL that appreciates the usage of mutually exploration and exploitation activities is a necessary condition for managers to improve an organization's innovation capability (Donate \& de Pablo, 2015). Furthermore, leadership directs employees on how to obtain and compile 
knowledge, which leads to the effective exploration and exploitation of knowledge, termed as inbound open innovation. In view of these arguments it is hypothesize that:

H1: KOL positively associated with inbound OI.

\section{Knowledge-Oriented-Leadership and Outbound Open Innovation}

Outbound OI indicates that organizations look for outside performers that have superior fitting business plans to exploit and popularize a specific innovation, rather than simply relying upon interior methods to market (Chesbrough, 2003). Past investigations have explored the facilitating role of KOL in outbound OI (Naqshbandi \& Jasimuddin, 2018). Others have also examined how leaders inspire and influence their employees to share and use ideas that prompt the effective exploitation of innovative knowledge, by boosting commercialization of an organization's knowledge (Bryant, 2003). Additionally, appreciate their employees to exploit an organization's knowledge assets by recognizing a method of appreciation, which they embrace, relying on the environment of movement, they wish to enhance in the subordinates (Chang, Hsu, \& Yen, 2012). However, KM in the firm must be started carefully by KOL who are highly proficient in handling this process (Dahlander\& Gann, 2010). Therefore, leaders are needed, who possess skills in KM, and therefore, improves innovation results in the organization (Naqshbandi \& Jasimuddin, 2018). According to Williams and Sullivan (2011) such leaders appreciate employees through incentives and empowerment to take liabilities in applying innovative knowledge techniques which result in efficient distribution and commercialization of ideas. As a result, outbound open innovation of an organization can be facilitated in this way. Consequently, it is hypothesized that:

H2: KOL positively associated with outbound OI

\section{Knowledge-Oriented-Leadership, Knowledge-Infrastructure-Capability and Open Innovation}

To confirm the significant use of knowledge sources, organization's need to have an infrastructure that contains technological, structural capabilities and an encouraging organization culture (Naqshbandi \& Jasimuddin, 2018). KOL helps in improving knowledge infrastructure of organization's by prompting their culture, structure and technology setup (Williams \& Sullivan, 2011), and by also executing the roles of directing and encouraging their employees. This is frequently done by developing, encouraging and rewarding the formation of innovative concepts that are in turn facilitated by increasing a culture and structure of an organization(Jones, Herschel, \& Moesel, 2003; Williams \& Sullivan, 2011). In addition, knowledge-oriented-leaders train, envision and inspire their employees to distribute and apply the knowledge and innovative concepts which they produce from inside or outside resources (Williams \& Sullivan, 2011). Likewise, knowledge-oriented leaders support the advancement of knowledge infrastructure of organizations by prompting their technological, cultural and structural infrastructure capabilities. In this regard, this sort of leadership also plays the roles of counseling and inspiring their followers. Naqshbandi and Jasimuddin (2018) stated that KOL facilitates KM infrastructure that contains technology, culture and structures, which in turn builds the KM capability of a firm. Therefore, based on the literature it is hypothesized that: 
H3: KOL has a significant positive impact on KIC of organization.

Furthermore, knowledge infrastructure is not exclusively focused on innovation, but it builds an atmosphere that causes the innovation to take place (Du Plessis, 2007). OI is the most knowledge-based-process which requires the organization to consistently renew its knowledge and combine its existing assets to create new ideas (Cantner, Joel \& Schmidt, 2011). Accordingly, the main task of the innovating organization is to position existing knowledge resources and assets and discover innovative knowledge (Nonaka \& Takeuchi, 1995). In view of Akram, Siddiqui \& Nawaz (2011) a firms knowledge resources are the heart of innovation because they extend the knowledge capability of the firm that leads to OI. In addition, Hajir, Obeidat, Al-dalahmeh and Masa'deh (2015) found a significant impact of KIC on innovation. Moreover, numerous studies have explored how an organization with healthier KnowledgeInfrastructure outclasses their opponents in terms of innovative results (Donate \& de Pablo, 2015; Jones et al., 2003; Naqshbandi \& Jasimuddin, 2018).

These researchers have admitted that applying new technology and building a firm's culture that supports to utilize knowledge that performs a critical role in improving an organization's innovative performance including the growth of innovative products. The knowledge infrastructure capability, supported by competent technological systems, supports a sustained record of knowledge resources. Additionally, a supportive firm's structure can help proper and improper communication within a firm, whereas an inspiring culture facilitates formation of innovative ideas and knowledge(Donate \& de Pablo, 2015; Islam, Jasimuddin, \& Hasan, 2015).Consequently, KOL encourages the improvement of KIC of an organization which, in turn, assists inbound and outbound OI. Therefore, it is hypothesized that:

H4: KIC has a significant positive impact on inbound OI.

H5: KIC has a significant positive impact on outbound OI.

H6: KIC has significant mediating role in the relationship between KOL and inbound OI.

H7: KIC has significant mediating role in the relationship between KOL and outbound OI.

\section{Knowledge-Oriented-Leadership, Knowledge-Infrastructure-Capability and Open Innovation}

To ensure the best use of knowledge, organizations are required to have a well balance process management system such as acquisition, sharing and application of knowledge. Leadership and factors such as developed reward structures and communication network affect these systems as encouragement and incentives cultivate innovative concepts (Ho, 2009; Naqshbandi \& Jasimuddin, 2018; Ribiere \& Sitar, 2003; Williams \& Sullivan, 2011). Several studies have highlighted the facilitating role of KM processes in the betterment and sharing knowledge through proper and improper communication channels, and show that leadership can influence an organization's capabilities to make and assimilate innovative ideas (Donate \& de Pablo, 2015; García-Morales, Llorens-Montes, \& Verdú-Jover, 2006; Lakshman \& Parente, 2008; Naqshbandi \& Jasimuddin, 2018; Sarin \& McDermott, 2003).Therefore, it is hypothesized that:

H8: KOL has a significant Positive impact on KPC of organization 
Furthermore, KPC including acquisition, application, and sharing are highly linked with innovation outcome (Donate \& de Pablo, 2015; Kamasak, Yozgat, \& Yavuz, 2017), and firms which establish capabilities in distributing knowledge can innovate well(Naqshbandi \& Jasimuddin, 2018).

Apposite combinations of KPC that are functionalized through various human and technology initiatives enable firms to disclose existing embedded organizational knowledge and create new knowledge (Yayavaram\& Chen, 2015). Furthermore, KPC support organizations to assign, allocate and modernize this gathered insignificant knowledge at all levels of organization (Easterby-Smith \& Prieto, 2008; Tranekjer \& Knudsen, 2012).

Therefore, proper operationalization of KPC improves the intellectual, commercial and innovative skills of an organization yielding numerous creative outcomes along with improving the connections with clients, contractors, institutions and a wide range of performers in the innovation structure (Wang \& Libaers, 2016).

The worth formation for an organization relies on intangible and knowledge sources(Grant, 1996; Wiklund \& Shepherd, 2003), which can be established internally from the research and development department or acquired from external sources (Scuotto, Santoro, Bresciani, \& Del Giudice, 2017). Several studies have examined how systems in organizations, which encourage innovative knowledge formation, division and execution, play vital roles in the improvement of innovative outcomes (Darroch, 2005. As a result, KOL promotes an organizational knowledge processes capability which, in turn, enhances OI performance. In the view of this it is hypothesized that:

H9: KPC has a significant positive impact on inbound OI.

H10: KPC has a significant positive impact on outbound OI.

H11 KPC has significant mediating role in the relationship between KOL and inbound OI.

H12: KPC has significant mediating role in the relationship between KOL and outbound OI.

\section{Research Methodology}

This research is quantitative in nature with explanatory and causative investigation that evaluates the relationship among KOL, and OI (inbound and outbound), with the mediating effects off KIC and KPC. This is a cross-sectional study with a deductive approach.

\section{Population and Sampling}

This study employs a survey to collect primary data for empirical analysis. Primary data are gathered from managers, assistant managers and management staff from the pharmaceutical and health department of Pakistan through structured questionnaires. 420 questionnaires were circulated to respondents from November 2018 to March 2019through personal visits, e-mail and an online survey. 340 were returned and after screening 305 valid responses were usable, with a response rate of $76.25 \%$. 


\section{Questionnaire and Measurements}

A comprehensive literature review was undertaken to establish the observed items regarding the assessment of the relationship among latent variables. The questionnaire was developed by adopting items from different studies and comprised of 64 questions in five sections. Respondents had to assess their management on a Likert scale from one (strongly disagree) to five (strongly agree) on all item scales. The first section of the questionnaire consists of the demographic information, which comprises questions about respondents age, organization age, education qualifications and experience. The second section focused on KOL and comprised six questions. While, the third section examines OI and contained five items. The fourth and fifth sections related to KPC and KIC with 13 and 37 items. KOL consists motivational and communication elements of transformational and transactional leadership styles. KOL was measured with six items adopted from the study of Donate and de Pablo (2015). Inbound and outbound OI were comprised of six and four items correspondingly. These both were measured with items adopted from the studies of Lichtenthaler (2009), Naqshbandi et al. (2016), Naqshbandi \& Jasimuddin (2018) and Sisodiya, Johnson, and Grégoire (2013). In addition, all items of inbound and outbound OI were rated on five points Likert scales. Furthermore, KPC consisted of three dimensions i.e. knowledge acquisition process, knowledge sharing process and knowledge application process. Four items for knowledge acquisition, five items for knowledge sharing and four items for knowledge application process are adopted from the study of Lin \& Lee (2005). All KPC items were rated on a five point Likert scale. KIP consists of three dimensions i.e. technological infrastructure, cultural infrastructure and structural infrastructure capability. 13 items for technological infrastructure, 12 items for cultural infrastructure and 12 items for structural infrastructure capability were adopted from the study of Gold et al. (2001).

\section{Statistical Procedure}

For testing the relationship between KOL, inbound and outbound OI, KPC and KIC of the organization and assess the predictive power of the model; structural equation modeling (SEM) is employed. PLS-SEM is used to analyze the research model and hypothesis testing, and the variance oriented approach is employed as smart PLS imposes less limitations on the sample size and distribution (Chin, Marcolin, \& Newsted, 2003). Smart PLS is based on the structure equation modelling approach, which simultaneously considers the theoretical structural and measurement model (Chin, 1998). In addition, multi-collinearity issues can be effectively resolved by using smart-PLS (Chin et al., 2003). In addition, quantitative technique is used to evaluate the data. Even though assessment of structural and measurement model arises simultaneously; the presentation of a smart PLS model usually takes place in two phases. The first phase is through confirmatory factor analysis for the assessment of the measurement model and to evaluate the validity and reliability of the latent variables. Then, evaluation of the structural model observes the (direct and indirect path) relationship among the variables in the research framework.

\section{Results and Analysis}




\section{Measurement Model:}

Method bias was measured through the common method variance using the single factor method. This was tested by forcing a single factor loading of all the items through exploratory factor analysis. The variance explained was 24\% showing the absence of common method bias (Mattila \& Enz, 2002; Podsakoff \& Organ, 1986). Moreover, the single factor model was also tested in AMOS which presented the model fitness indicators as $\chi^{2}=2847.16, \mathrm{DF}=793, \mathrm{CFI}=0.579$, NFI $=0.486$ and RMSEA $=0.095$. These poor indices confirm the earlier finding that common method bias is not detected in the data (Mattila \& Enz, 2002; Podsakoff \& Organ, 1986). Non-response bias was tested through the t-test (Armstrong \& Overton, 1977), where respondents with missing demographic values were considered non-respondents (Kam \& Meyer, 2015)

\section{Reliability of the constructs}

The construct reliability of the measurement model was assessed through Cronbach's alpha and composite reliability (as shown in table1). The values of Cronbach's alpha of all constructs are greater than 0.7, which is acceptable (Werts, Linn, \& Jöreskog, 2007). Additionally, for further strengthens the assessment of reliability of the construct; The composite reliability of the constructs are also calculated because it is commonly admitted that composite reliability is a more significant tool to measure the reliability than Cronbach's alpha (Werts et al., 2007). The values of composite reliability of all the constructs are also greater than 0.7 that further toughens the assessment of reliability of all the variables. Furthermore, individual items reliabilities are also reported in the table 1 and assessed through factor loadings of the items on the corresponding constructs. Only those Items which contain factor loading equal or greater than 0.5; have been considered significant and retained in the model Hair Jr el al. (2016).

Table 1: Measurement properties of research model in smart

\begin{tabular}{|c|c|c|c|c|c|c|c|c|}
\hline Variables & Dimension & items & $\begin{array}{c}\text { factor } \\
\text { loading }\end{array}$ & Mean & SD & $\mathbf{A}$ & CR & AVE \\
\hline \multirow[t]{5}{*}{ KOL } & & KOL2 & 0.643 & 3.97 & 0.8 & 0.82 & 0.87 & 0.58 \\
\hline & & KOL3 & 0.732 & & & & & \\
\hline & & KOL4 & 0.783 & & & & & \\
\hline & & KOL5 & 0.804 & & & & & \\
\hline & & KOL6 & 0.838 & & & & & \\
\hline \multirow[t]{12}{*}{ KIC } & TIC & TIC1 & 0.724 & 3.13 & 0.88 & 0.91 & 0.92 & 0.6 \\
\hline & & TIC2 & 0.736 & & & & & \\
\hline & & TIC3 & 0.784 & & & & & \\
\hline & & TIC4 & 0.788 & & & & & \\
\hline & & TIC5 & 0.779 & & & & & \\
\hline & & TIC6 & 0.768 & & & & & \\
\hline & & TIC7 & 0.796 & & & & & \\
\hline & & TIC8 & 0.797 & & & & & \\
\hline & CIC & $\mathrm{CIC} 1$ & 0.726 & 4.11 & 0.67 & 0.89 & 0.9 & 0.5 \\
\hline & & $\mathrm{CIC} 2$ & 0.835 & & & & & \\
\hline & & CIC4 & 0.589 & & & & & \\
\hline & & CIC5 & 0.768 & & & & & \\
\hline
\end{tabular}




\begin{tabular}{|c|c|c|c|c|c|c|c|c|}
\hline & & CIC6 & 0.769 & & & & & \\
\hline & & CIC10 & 0.770 & & & & & \\
\hline & & CIC11 & 0.779 & & & & & \\
\hline & & CIC12 & 0.520 & & & & & \\
\hline & & CIC13 & 0.556 & & & & & \\
\hline & SIC & SIC3 & 0.785 & 3.64 & 0.55 & 0.92 & 0.93 & 0.68 \\
\hline & & SIC4 & 0.823 & & & & & \\
\hline & & SIC5 & 0.907 & & & & & \\
\hline & & SIC6 & 0.883 & & & & & \\
\hline & & SIC7 & 0.851 & & & & & \\
\hline & & SIC8 & 0.680 & & & & & \\
\hline \multirow[t]{10}{*}{ KPC } & KAP & KAP2 & 0.894 & 4.4 & 0.53 & 0.82 & 0.78 & 0.54 \\
\hline & & KAP3 & 0.622 & & & & & \\
\hline & & KAP4 & 0.663 & & & & & \\
\hline & KA & KA1 & 0.825 & 3.97 & 0.78 & 0.83 & 0.86 & 0.62 \\
\hline & & KA2 & 0.854 & & & & & \\
\hline & & KA3 & 0.888 & & & & & \\
\hline & & KA4 & 0.525 & & & & & \\
\hline & KSP & KSP1 & 0.869 & 3.5 & 0.83 & 0.78 & 0.86 & 0.67 \\
\hline & & KSP2 & 0.845 & & & & & \\
\hline & & KSP3 & 0.726 & & & & & \\
\hline \multirow[t]{5}{*}{ IOI } & & IOI1 & 0.777 & 4.07 & 0.82 & 0.84 & 0.88 & 0.6 \\
\hline & & IOI2 & 0.724 & & & & & \\
\hline & & IOI3 & 0.802 & & & & & \\
\hline & & IOI4 & 0.784 & & & & & \\
\hline & & IOI5 & 0.787 & & & & & \\
\hline \multirow[t]{4}{*}{ OOI } & & OOI1 & 0.763 & 3.56 & 0.75 & 0.73 & 0.82 & 0.54 \\
\hline & & OOI2 & 0.823 & & & & & \\
\hline & & OOI3 & 0.672 & & & & & \\
\hline & & OOI4 & 0.668 & & & & & \\
\hline
\end{tabular}

\section{Validity of the constructs}

There are two tools used in Smart-PLS for assessing the validity of the instruments. Moreover, the present study calculated the measurement model by means of assessing the convergent validity in accordance with Hair Jr et al. (2016) by looking at the values of average variance extracted $(>0.5)$, and composite reliability $(>0.7)$. As presented in Table 1, all the values exceeded the threshold suggested and thus, the convergent validity was confirmed. 
In assessing the discriminant validity, the study followed the guidelines from Fornell \& Larcker (1981), whereby the square root of the average variance extracted should be higher than the row and column values of the correlations. As shown in Table 2, all the values on the diagonal exceeded the row and column values, thus confirming adequate discriminant validity.

\section{Structural Model}

As presented in Figure 1 in order to test direct relations, direct effect analysis was used to assess the hypotheses. Bootstrapping (1000 subsamples) was used to assess the significance of the path coefficient and calculate the standard error with $\mathrm{P}$ and $\mathrm{T}$-values providing direct evidence of the hypotheses being accepted or rejected. Table 2 displays the results of the structural model analysis, showing the path coefficients along with their significance levels. The results confirmed that only seven out of eight direct effects were significant and, it can be concluded that H2, H3, H4, H5, H8, H9, and H10 were supported, while H1 was not supported.

To test the mediation hypotheses, the process macro was utilized by means of a bootstrapping indirect method (Preacher \& Hayes, 2004, 2008). The bootstrapping analysis, demonstrated that all four out of the four indirect effects were significant (Table 2) and, as indicated by Preacher and Hayes (2008), the indirect effect did not straddle 0 in between, indicating that there is mediation. Thus, the researchers can conclude that the mediation effects are statistically significant, which indicates that $\mathrm{H} 6, \mathrm{H} 7, \mathrm{H} 11$, and $\mathrm{H} 12$, were supported.

Table 2. Discriminant validity

\begin{tabular}{cccccccccc}
\hline & CIC & IOI & KA & KAP & KOL & KSP & OOI & SIC & TIC \\
\hline CIC & 0.709 & & & & & & & & \\
IOI & 0.515 & 0.775 & & & & & & & \\
KA & 0.614 & 0.541 & 0.787 & & & & & & \\
KAP & 0.068 & 0.043 & 0.068 & 0.736 & & & & & \\
KOL & 0.498 & 0.432 & 0.509 & 0.150 & 0.763 & & & \\
KSP & 0.501 & 0.491 & 0.785 & 0.049 & 0.411 & 0.816 & & & \\
OOI & 0.510 & 0.482 & 0.577 & 0.085 & 0.630 & 0.576 & 0.734 & & \\
SIC & 0.192 & 0.157 & 0.268 & -0.075 & 0.099 & 0.283 & 0.204 & 0.825 & \\
TIC & 0.146 & 0.110 & 0.098 & -0.104 & 0.141 & 0.076 & 0.183 & 0.064 & 0.772 \\
\hline
\end{tabular}

Note:DiagonalValuesarethesquarerootofAverageVarianceExtracted(AVE)

Table 2. Hypothesis Testing 
95\% Bootstrap BCI

\begin{tabular}{cccccc}
\hline Hypotheses & Relationship & Std. Beta & Std. Error & T-Value & P Values \\
\hline H1 & KOL -> IOI & 0.151 & 0.084 & 1.848 & 0.065 \\
H2 & KOL -> OOI & 0.387 & 0.060 & 6.472 & 0.000 \\
H3 & KOL -> KIC & 0.019 & 0.005 & 3.157 & 0.002 \\
H4 & KIC - > IOI & 0.207 & 0.077 & 2.626 & 0.009 \\
H5 & KIC -> OOI & 0.162 & 0.054 & 2.883 & 0.004 \\
H6 & KOL -> KIC -> IOI & 0.004 & 0.002 & 2.077 & 0.038 \\
H7 & KOL -> KIC -> OOI & 0.003 & 0.001 & 2.075 & 0.038 \\
H8 & KOL -> KPC & 0.021 & 0.005 & 3.983 & 0.000 \\
H9 & KPC -> IOI & 0.355 & 0.066 & 5.409 & 0.000 \\
H10 & KPC -> OOI & 0.326 & 0.073 & 4.543 & 0.000 \\
H11 & KOL -> KPC -> IOI & 0.007 & 0.002 & 3.533 & 0.000 \\
H12 & KOL -> KPC -> OOI & 0.007 & 0.002 & 3.329 & 0.001 \\
\hline
\end{tabular}

${ }^{*} \mathrm{p}<0.05 ; \mathrm{KOL}=$ Knowledge oriented-leader-ship; IOI= In-bound open in-novation; OOI= Out-bound open innovation; $\mathrm{KPC}=\mathrm{KPC}, \mathrm{KAP}=\mathrm{Knowledge}$ acquisition process. $\mathrm{KAP}=$ knowledge application process; $\mathrm{KSP}=$ Knowledge sharing process; $\mathrm{KIC}=$ Knowledge infrastructure cap-ability; $\mathrm{TIC}=$ technological infrastructure capability; CIC $=$ cultural infrastructure cap-ability; SIC = structural infrastructure cap-ability

\section{Discussion}

The first objective of this study was to analyze the level to which KOL effects two-dimensional $\mathrm{OI}$ (inbound and outbound $\mathrm{OI}$ ). Hypotheses $\mathrm{H} 1$ and $\mathrm{H} 2$ proposed that KOL facilitates inbound and outbound OI. The findings of H1 do not support that KOL has significant association with inbound OI. Even though the previous study of Naqshbandi and Jasimuddin (2018) found significant relationships between these two variables. The findings of this research are unique based on several differencess between these two studies, such as cultural difference, firm difference and there is a huge mind set difference of employees of the organizations toward innovation outcomes.

Based on these results it can be concluded that leadership in health and pharmaceutical organizations is only the most important source that can take the firm to its proposed target in competitive and innovative objectives through their KM initiatives. However, on the other hand this study found support for the relationship between KOL and outbound OI. The findings of the research support this relationship, leading to the decision that leaders motivate and empower their subordinates to share and apply ideas to the effective exploitation of new knowledge, by appreciating the commercialization of an organization's knowledge. The findings of this research confirm the previous literature (García-Morales et al., 2006; Naqshbandi \& Jasimuddin, 2018; Sarin \& McDermott, 2003) which also highlights the supporting, encouraging and stimulating role of leaders in knowledge sharing and application.

The second objective of the research was to investigate the causal relationship among KOL, KIC, and OI (inbound and outbound) and the mediating role of KIC between KOL and OI. Hypothesis 3 proposed that KOL has a significant impact on KIC. The findings of the research support this link, leading to the decision that KOL establishes an organization KIC, such as technology, structure and culture (Naqshbandi \& Jasimuddin, 2018). García-Morales et al. 
(2006) add that leaders clarify a firm's objectives and values to the followers, which sets a way for them to work with innovative ideas. Furthermore, leaders allocate roles and duties to employees by recognizing their expertise and abilities and creating optimal use of their potential innovative ideas (Viitala, 2004). Leaders can also encourage effective exploration of knowledge by facilitating followers with new technology and motivate them to use new technical structures that confirm the effective flow of information and its integration (Lakshman., 2005). Furthermore, Hypotheses 4 and 5 proposed that KOL has a significant impact on two-dimensional OI.

This study found support for these linkages, signifying that applying innovative technology and building an optimistic firm's culture facilitates to utilize knowledge that performs a critical role in enhancing an organization's advanced outcome including the growth of innovative performance. Numerous studies have explored that organizations with a healthier knowledge infrastructure outclass their opponents in terms of innovative results (Donate \& de Pablo, 2015; Jones et al., 2003; Naqshbandi \& Jasimuddin, 2018).

In addition, Hypotheses 6 and 7 proposed that KIC mediates the relationship between KOL and OI (inbound and outbound). The findings confirmed that KIC of organizations serve as a mechanism between KOL and inbound and outbound OI. This leads to the decision that KOL establishes organizations KIC such as technology, structure and culture, which in turns enhances organizational innovation outcomes. In view of Du Plessis (2007) state that knowledge infrastructure is not exclusively focused on innovation, but it generates an atmosphere which helps the innovation to take place.

Based on the findings, it can be concluded that pharmaceutical companies and health sectors can use KOL to develop KIC to encourage their employees in their endless inbound and outbound OI performance. It is recommended that leaders who support exploitation and exploration of knowledge helps organizations become more capable in dealing with knowledge by supporting their infrastructure and process.

The third objective of the research has been to analyze the causal relationship among KOL, KPC, and OI (inbound and outbound) and the mediating role of KPC between KOL and OI. Hypothesis 8 proposed that KOL has a significant impact on KPC. This leads to the conclusion that leadership plays an imperative role in influencing an organization's process capability of acquisition, application and sharing knowledge of a firm. KOL is the critical element of total knowledge process of organization who perform as role models, originators, promoters, and consultants in stimulating successful usage of know-ledge of the organization.

Furthermore, leaders help facilitate organizational processes that encourage the dissemination and implementation of new ideas for commercialization. Several studies (Lakshman., 2005) have recognized that leaders influence the KPC of an organization by improving direct and indirect means of communication and can influence an organization's capabilities to make and assimilate new ideas. In addition, Hypotheses 9 and 10 proposed that KPC has a significant impact on inbound and outbound OI. The findings support these links by suggesting that organizations with better KM processes can innovate better. 
In addition, KPC support an organization when assigning, allocating and modernizing the gathered insignificant knowledge at all levels of organization (Easterby-Smith \& Prieto, 2008; Tranekjer \& Knudsen, 2012). Additionally, KPC of organizations with knowledge acquisition, application and sharing processes are closely linked with significant innovative performance (Donate \& Pablo, 2015; Kamasak, Yozgat, \& Yavuz, 2017), and Companies that build their capabilities in handling out knowledge can innovate better (Jasimuddin \& Naqshbandi, 2017). In view of Darroch (2005) Systems in organizations which are encouraging for innovative knowledge creation, integration and implementation play critical roles in the improvement of innovative performance.

Finally, Hypotheses 11 and 12 proposed that KPC mediates the relationship between KOL and inbound and outbound OI. The findings confirmed that KPC serves as a mechanism between KOL and two-dimensional OI. Leadership plays a domineering role in influencing organization's process capabilities of acquisition, application and sharing knowledge of a firm, that encourage the dissemination and implementation of new ideas for commercialization. Furthermore, several studies have highlighted (Donate \& Pablo, 2015; García-Morales, Llorens-Montes, \& Verdú-Jover, 2006; Jasimuddin \& Naqshbandi, 2017; Lakshman, 2005; Sarin \& McDermott, 2003) the supporting role of KM processes in the advancement and sharing of knowledge through proper and improper communication channels, and leadership influence an organization's capabilities to make and assimilate innovative ideas. In conclusion, KPC of the organization is marked by supportive acquisition, application and sharing of knowledge promoted by knowledge leaders; and is favorable for testing for innovative ideas.

\section{Practical Contribution}

To stay innovative organizations are required to manage their knowledge effectively (Carneiro, 2000) and KM can help organizations handle the inflow and outflow of knowledge. Many firms currently engage in KM by adopting the OI (inbound and outbound) paradigm, in order to hold knowledge both within their organization and outwardly to their stakeholders (Naqshbandi \& Jasimuddin, 2018). Consequently, organizations can enhance their innovative outcome by both attaining knowledge and technologies from exterior resources and appointing outer paths to exploit their own knowledge. Several scholars have argued that leadership provides a way to accomplish organizational objectives (Shamim et al., 2017). This study's findings indicate that leadership is one of the most crucial sources that can facilitate an organization in achieving its desired destination in advanced and competitive objectives through knowledge management inventiveness(Bryant, 2003; Singh, 2008). In addition, this investigation recommends that organizations should appoint and encourage such leaders, who are experienced with the skills of producing, converting, storing and applying knowledge resources. When companies employ such front-runners, they will improve the expansion and division of innovative knowledge, which will result in active exploration of new ideas. These ideas can be efficiently converted, combined and executed to improve innovative products, leading to organization effectiveness (Bryant, 2003)

Health and pharmaceutical companies should motivate their management to follow the KOL style. Organizations who have KOL managers are well equipped with KM capabilities to 
procure, integrate, utilize and convert external knowledge and sources. This will promote companies OI outcomes through efficiently internalizing and commercializing their innovative resources. Furthermore, organizations can use KOL to develop KIC and KPC to motivate their employees in their nonstop inbound and outbound OI performance. It is proposed that leaders who help knowledge investigation and utilization, facilitate companies into becoming more effective in dealing knowledge by developing their infrastructure and improving their process for the enhancement of innovative outcomes(Naqshbandi \& Jasimuddin, 2018). This leadership style forms the structure and culture of an organization and moves them in the direction of achieving innovative outcomes. KOL also makes the ultimate use of technology to produce, spread and execute new ideas.

This leadership style sets examples for followers by following organization' s knowledge procedures and this motivates the behavior among subordinates through an encouragement system. It is recommended that organizations must support such leaders and strive to facilitate systems and infrastructures that support speedy and efficient flow of knowledge to the right sources where it can be utilized to create worth. Leadership should be motivated to bring such sort of systems and technologies into practice to organization can take advantages from its information sources. It is expected that this study will assist as a guideline for the firms who are struggling to achieve competitive benefits through outclassing their competitors through innovation.

\section{Theoretical contribution}

This study expands the literature in four sectors i.e. KOL, KPC, KIC and OI (inbound and outbound). By suggesting an incorporated model extracted from leadership theory and knowledge-based theory of the organization, this study suggests connection of these concepts. Furthermore, this study subsidizes the theoretical improvement of a conceptual model for enlightening the relationships among KOL, KIC, KPC and inbound and outbound OI.

The connection between KOL and OI (inbound and outbound) has received limited attention in leadership and innovation literature (Donate \& de Pablo, 2015; Lakshman., 2005). However, many identify the role of transformational and transactional leadership in influencing an organization's innovation performance (Gumusluoglu\& Ilsev, 2009; Jung, Chow, \& Wu, 2003; Pieterse, van Knippenberg, Schippers, \& Stam, 2009). Furthermore, Bryant (2003) stated that obtaining innovative results demands leaders to show a blend of leadership styles. The specific leadership style identified was KOL, which is mixture of transformation and transactional leadership styles. In addition, (Donate \& de Pablo, 2015) argue that knowledge- orientedleaders with the support of KM make use of leadership-styles, communication, motivation, preferment and employment, and lead to an organization's innovation outcome. Naqshbandi \& Jasimuddin (2018) explored the effects of KOL on OI through KM capabilities. This study, however, emphases the indirect role of KOL and OI (inbound and outbound) through KIC and KPC. This research also investigated the direct effect of variables. By arguing the concept of leverage innovation through cross-boundary knowledge influxes and outflows, this study explored the mediating role of KIC and KPC in enhancing OI outcomes, thereby adding to the efforts of Donate \& de Pablo (2015) and Naqshbandi \& Jasimuddin (2018). 


\section{Conclusion}

This study examined the impact of KOL on KIC and KPC: and KIC and KPC on OI (inbound and outbound) and investigated the mediating role of KIC and KPC between KOL and OI. The findings of the research confirm that KOL does not play an important role in inbound OI of the organization. However, this study confirmed the significant role of KOL in outbound OI. Furthermore, KOL was found to be a strong predictor of KIC and KPC; and this study found significant impact of KIC and KPC on two-dimensional OI. Another finding of the research is that KOL impacts on OI via KIC and KPC, confirming the mediating role of KIC and KPC. This study extends the literature on KOL, KIC, KPC and two-dimensional OI in the context of pharmaceutical and health sectors.

\section{Research Limitations and Future Directions}

Firstly, this study is limited as it focused on the pharmaceutical and health sectors in Pakistan. It is suggested to repeat the study in other sectors and additional countries to accommodate the issue of generalizability, e.g. IT industry, aviation, defense production setups, manufacturing industries and the chemical industry. Secondly, this research investigated a productive type of leadership style, KOL, in stimulating innovation. Future studies can evaluate negative types of leadership style, such as laissez faire leadership or passive leadership, and could relate to the two types of innovation inbound and outbound OI (Einarsen, Aasland, \& Skogstad, 2007; Naqshbandi \& Jasimuddin, 2018; Skogstad, Einarsen, Torsheim, Aasland, \& Hetland, 2007). Thirdly, KIC and KPC should be examined as a separate moderator on the basic relationship between KOL and two-dimensional OI. Fourthly, for further strengthening the relationship, the constructs of KIC (technological, cultural, and structural infrastructure capability) and KPC (knowledge acquisition, application and knowledge sharing capability) can be examined as a separate mediator between the KOL and OI relationship. Lastly, Forthcoming studies should place more emphasis on longitudinal studies or mixed method can be used for compensating the weaknesses of individual methods and study must be based on a larger sample, preferably in more than one country.

\section{References}

Ades, C., Figlioli, A., Sbragia, R., Porto, G., AryPlonski, G., \& Celadon, K. (2013). Implementing Open Innovation: The Case of Natura, IBM and Siemens. Journal of Technology Management \& Innovation, 8(SPL.ISS.1), 113-114. https://doi.org/10.4067/S0718-27242013000300057

Akram, K., Siddiqui, S. H., \& Nawaz, M. A. (2011). Role of knowledge management to bring innovation: an integrated approach. 92(333), 6183035.

Alavi, M., \&Leidner, D. (2001). Knowledge management and knowledge management systems: Conceptual foundations and research issues. 107-136.

Armstrong, J. S., \& Overton, T. S. (1977). Estimating nonresponse bias in mail surveys. 14(3), 396-402. 
Bhatt, G. D. (2001). Knowledge management in organizations: examining the interaction between technologies, techniques, and people. Journal of Knowledge Management, 5(1), 68-75. doi:10.1108/13673270110384419

Bigliardi, B., \& Galati, F. (2016). Which factors hinder the adoption of open innovation in SMEs? Technology Analysis and Strategic Management, 28(8), 869885.https://doi.org/10.1080/09537325.2016.1180353

Bigliardi, B., \& Galati, F. (2018). An Open Innovation Model for SMEs. In Researching Open Innovation in SMEs (pp. 71-113). WORLD SCIENTIFIC. https://doi.org/10.1142/9789813230972_0003

Bigliardi, B., Galati, F., \&Petroni, A. (2014). How to effectively manage knowledge in the construction industry. Measuring Business Excellence, 18(3), 57-72. https://doi.org/10.1108/MBE-10-2013-0055

Bogers, M., Zobel, A. K., Afuah, A., Almirall, E., Brunswicker, S., Dahlander, L., ... Ter Wal, A. L. J. (2017). The open innovation research landscape: established perspectives and emerging themes across different levels of analysis. Industry and Innovation, 24(1), 8-40. https://doi.org/10.1080/13662716.2016.1240068

Bolisani, E., \&Bratianu, C. (2017). Knowledge strategy planning: an integrated approach to manage uncertainty, turbulence, and dynamics. Journal of Knowledge Management, 21(2), 233-253. https://doi.org/10.1108/JKM-02-2016-0071

Brunswicker, S., \& Chesbrough, H. (2018). The Adoption of Open Innovation in Large Firms. ResearchTechnology Management, 61(1), 35-45. https://doi.org/10.1080/08956308.2018.1399022

Bryant, S. E. (2003). The role of transformational and transactional leadership in creating, sharing and exploiting organizational knowledge. Journal of Leadership \& Organizational Studies, 9(4), 32-44.

Cantner, U., Joel, K., \& Schmidt, T. (2011). The effects of knowledge management on innovative success - An empirical analysis of German firms. Research Policy, 40(10), 1453-1462. doi:10.1016/j.respol.2011.06.007

Carneiro, A. (2000). How does knowledge management influence innovation and competitiveness? Journal of Knowledge Management, 4(2), 87-98. doi: $10.1108 / 13673270010372242$

Chang, C. M., Hsu, M. H., \& Yen, C. H. (2012). Factors affecting knowledge management success: the fit perspective. Journal of Knowledge Management, 16(6), 847-861. doi:10.1108/13673271211276155

Chesbrough, H. (2003). The logic of open innovation: managing intellectual property. 45(3), $33-58$.

Chesbrough, H. (2010). Open services innovation: Rethinking your business to grow and compete in a new era: John Wiley \& Sons.

Chesbrough, H., \&Bogers, M. (2014). Explicating open innovation: Clarifying an emerging paradigm for understanding innovation. New Frontiers in Open Innovation. Oxford: Oxford University Press, Forthcoming, 3-28.

Chesbrough, H., \& Crowther. (2006). Beyond high tech: early adopters of open innovation in other industries. 36(3), 229-236. 
Chin, W. W. (1998). The partial least squares approach to structural equation modeling. Modern methods for business research, 295(2), 295-336.

Chin, W. W., Marcolin, B. L., \&Newsted, P. R. (2003). A Partial Least Squares Latent Variable Modeling Approach for Measuring Interaction Effects: Results from a Monte Carlo Simulation Study and an Electronic-Mail Emotion/Adoption Study. Information Systems Research, 14(2), 189-217. doi:10.1287/isre.14.2.189.16018

Dahlander, L., \& Gann, D. M. (2010). How open is innovation? Research Policy, 39(6), 699709. doi:10.1016/j.respol.2010.01.013

Damodaran, L., \&Olphert, W. (2000). Barriers and facilitators to the use of knowledge management systems. Behaviour\& Information Technology, 19(6), 405-413.

Darroch, J. (2005). Knowledge management, innovation and firm performance. Journal of Knowledge Management, 9(3), 101-115. doi:10.1108/13673270510602809

Darroch, J., \& McNaughton, R. (2002). Examining the link between knowledge management practices and types of innovation. Journal of Intellectual Capital, 3(3), 210-222. doi:10.1108/14691930210435570

Davenport, T. H., De Long, D. W., \& Beers, M. C. (1998). Successful knowledge management projects. Sloan management review, 39(2), 43-57.

Del Giudice, M., Manlio Del Giudice, P., Vincenzo Maggioni, P., \&Maggioni, V. (2014). Managerial practices and operative directions of knowledge management within interfirm networks: a global view. Journal of Knowledge Management, 18(5), 841-846. doi:10.1108/jkm-06-2014-0264

DeTienne, Dyer, G., Hoopes, C., \& Harris. (2004). Toward a model of effective knowledge management and directions for future research: Culture, leadership, and CKOs. 10(4), 26-43.

Dezi, A. F. G. S. L. (2017). How MNC's subsidiaries may improve their innovative performance? The role of external sources and knowledge management capabilities. Journal of Knowledge Management, 21(3).https://doi.org/10.1108/JKM-09-2016-0411

Donate, M. J., \& de Pablo, J. D. S. (2015). The role of knowledge-oriented leadership in knowledge management practices and innovation. Journal of Business Research, 68(2), 360-370.

du Plessis, M. (2007). The role of knowledge management in innovation. Journal of Knowledge Management, 11(4), 20-29. doi:10.1108/13673270710762684

Easterby-Smith, M., \& Prieto, I. M. (2008). Dynamic capabilities and knowledge management: an integrative role for learning? British journal of management, 19(3), 235-249.

Eckhardt, J. T., Ciuchta, M. P., \& Carpenter, M. (2018). Open innovation, information, and entrepreneurship within platform ecosystems. Strategic Entrepreneurship Journal, 12(3), 369-391. https://doi.org/10.1002/sej.1298

Einarsen, S., Aasland, M. S., \&Skogstad, A. (2007). Destructive leadership behaviour: A definition and conceptual model. The Leadership Quarterly, 18(3), 207-216. doi:10.1016/j.leaqua.2007.03.002

Elenkov, D. S., \&Manev, I. M. (2005). Top management leadership and influence on innovation: The role of sociocultural context. Journal of Management, 31(3), 381402. 
Enkel, E., Gassmann, O., \& Chesbrough, H. (2009). Open R\&D and open innovation:exploring the phenomenon. 39(4), 311-316.

Fornell, C., \&Larcker, D. F. (1981). Structural equation models with unobservable variables and measurement error: Algebra and statistics: SAGE Publications Sage CA: Los

Angeles, CA. García-Morales, V. J., Llorens-Montes, F. J., \&Verdú-Jover, A. J. (2006). Antecedents and consequences of organizational innovation and organizational learning in entrepreneurship. Industrial Management \& Data Systems, 106(1), 2142. doi:10.1108/02635570610642940

Galati, F., Bigliardi,B., \&Petroni, A. (2016). Open innovation in food firms: Implementation strategies, drivers and enabling factors. International Journal of Innovation Management, 20(3), 1-24. https://doi.org/10.1142/S1363919616500420

Giudice, M. Del, \&Maggioni, V. (2014). Managerial practices and operative directions of knowledge management within inter-firm networks: A global view. Journal of Knowledge Management, 18(5), 841-846. https://doi.org/10.1108/JKM-06-2014-0264

Gold, A. H., Malhotra, A., \&Segars, A. H. (2001). Knowledge management: An organizational capabilities perspective. Journal of Management Information Systems, 18(1), 185-214.

Grant, R. M. (1996). Toward a knowledge-based theory of the firm. Strategic Management Journal, 17(S2), 109-122.

Greco, M., Grimaldi, M., \&Cricelli, L. (2019). Benefits and costs of open innovation: the BeCO framework. Technology Analysis \& Strategic Management, 31(1), 53-66. https://doi.org/10.1080/09537325.2018.1484442

Gumusluoglu, L., \&Ilsev, A. (2009). Transformational leadership, creativity, and organizational innovation. Journal of Business Research, 62(4), 461-473. doi:10.1016/j.jbusres.2007.07.032

Hajir, J., Obeidat, B. Y., Al-dalahmeh, M. A., \&Masa'deh. (2015). The role of knowledge management infrastructure in enhancing innovation at mobile telecommunication companies in Jordan. European Journal of Social Sciences, 50(3), 313-330.

Han, Oh, Im, Chang, Oh, \&Pinsonneault. (2012). Value Cocreation and Wealth Spillover in

Open Innovation Alliances. MIS Quarterly, 36(1), 291. https://doi.org/10.2307/41410418

Hansen, M. T., Nohria, N., \& Tierney, T. (1999). What's your strategy for managing knowledge? Harvard Business Review, 77(2).

Ho, C. T. (2009). The relationship between knowledge management enablers and performance. Industrial Management \& Data Systems, 109(1), 98-117. doi:10.1108/02635570910926618

Hung, R. Y. Y., Lien, B. Y.-H., Yang, B., Wu, C.-M., \&Kuo, Y.-M. (2011). Impact of TQM and organizational learning on innovation performance in the high-tech industry. International Business Review, 20(2), 213-225. doi:10.1016/j.ibusrev.2010.07.001

Ili, S., Albers, A., \& Miller, S. (2010). Open innovation in the automotive industry. R\&D Management, 40(3), 246-255. https://doi.org/10.1111/j.1467-9310.2010.00595.x

Islam, M. Z., Jasimuddin, S. M., \& Hasan, I. (2015). Organizational culture, structure, technology infrastructure and knowledge sharing. Vine, 45(1), 67-88. doi:10.1108/vine-05-2014-0037 
Jasimuddin, S. M. (2008). A holistic view of knowledge management strategy. Journal of KnowledgeManagement, 12(2), $57-66$. https://doi.org/10.1108/13673270810859514

Jasimuddin, S. M., Connell, C., \& Klein, J. H. (2005). The challenges of navigating a topic to a prospective researcher: the case of knowledge management research. Management Research News, 28(1), 62-76. doi:10.1108/01409170510784715

Jones, N. B., Herschel, R. T., \&Moesel, D. D. (2003). Using "knowledge champions" to facilitate $0.1108 / 13673270310463617$

Jung, D. I., Chow, C., \& Wu, A. (2003). The role of transformational leadership in enhancing 4(4-5), 525-544. doi:10.1016/s1048-9843(03)00050-x

Kamasak, R., Yozgat, U., \& Yavuz, M. (2017). Knowledge process capabilities and innovation: testing the moderating effects of environmental dynamism and strategic flexibility. Knowledge Management Research \& Practice, 15(3), 356-368. doi:10.1057/s41275017-0068-4

Kant, R., \& Singh, M. (2009). Knowledge management implementation: modelling the variables. 6(3), 342-361.

Kodama, F., \& Shibata, T. (2015). Demand articulation in the open-innovation paradigm. Journal of Open Innovation: Technology, Market, and Complexity, 1(1), 2. https://doi.org/10.1186/s40852-015-0003y

Kogut, B., \& Zander, U. (1992). Knowledge of the Firm, Combinative Capabilities, and the Replication of Technology. Organization Science, 3(3), 383-397. doi:10.1287/orsc.3.3.383

Lakshman, C., \&Parente, R. C. (2008). Supplier-focused knowledge management in the automobile industry and its implications for product performance. Journal of Management Studies, 45(2), 317-342.

Lakshman. (2005). Top executive knowledge leadership: Managing knowledge to lead change atgeneral electric. Journal of Change Management, 5(4), 429-446. doi:10.1080/14697010500401540

Lauri, L., Heidmets, M., \&Virkus, S. (2016). The information culture of higher education institutions: the Estonian case. Information Research: An International Electronic Journal, 21(3), n3.

Lichtenthaler, U. (2009). Outbound open innovation and its effect on firm performance: examining environmental influences. R\&d Management, 39(4), 317-330.

Lin, H. F., \& Lee, G. G. (2005). Impact of organizational learning and knowledge management factors on e-business adoption. Management Decision, 43(2), 171-188. doi: $10.1108 / 00251740510581902$

Lin, T.-C., \& Huang, C.-C. (2008). Understanding knowledge management system usage antecedents: An integration of social cognitive theory and task technology fit. Information \& Management, 45(6), 410-417. doi:10.1016/j.im.2008.06.004

Loebbecke, C., van Fenema, P. C., \& Powell, P. (2016). Managing inter-organizational knowledge sharing. Journal of Strategic Information Systems, 25(1), 4-14. https://doi.org/10.1016/j.jsis.2015.12.002 
Lopez-Vega, H., Tell, F., \&Vanhaverbeke, W. (2016). Where and how to search? Search paths in open innovation. Research Policy, 45(1), 125-136. https://doi.org/10.1016/j.respol.2015.08.003

Mattila, A. S., \&Enz, C. A. (2002). The role of emotions in service encounters. 4(4), 268-277.

Mehmood, K., \& Hussain, A. (2017). Knowledge-oriented leadership and innovation: A mediating role of knowledge creation: A case of software industry. Paper presented at the 2017 4th International Conference on Systems and Informatics (ICSAI).

Mohsenabad, A. S., \&Azadehdel, M. (2016). The impact of knowledge-oriented leadership on innovation performance of manufacturing and commercial companies of Guilan province. 3(1), 884-897.

Naqshbandi, M. M., \&Jasimuddin, S. M. (2018). Knowledge-oriented leadership and open innovation: Role of knowledge management capability in France-based multinationals. International Business Review, 27(3), 701-713. doi:10.1016/j.ibusrev.2017.12.001

Naqshbandi, M. M., Garib Singh, S. K., \& Ma, P. (2016). The link between organisational citizenship behaviours and open innovation: A case of Malaysian high-tech sector. IIMB Management Review, 28(4), 200-211. doi:10.1016/j.iimb.2016.08.008

Nonaka, I., \& Takeuchi, H. (1995). The knowledge-creating company: How Japanese companies create the dynamics of innovation: Oxford university press.

Oltra, M. J., Flor, M. L., \& Alfaro, J. A. (2018). Open innovation and firm performance: the role of organizational mechanisms. Business Process Management Journal, 24(3), 814-836. https://doi.org/10.1108/BPMJ-05-2016-0098

Pieterse, A. N., van Knippenberg, D., Schippers, M., \& Stam, D. (2009). Transformational and transactional leadership and innovative behavior: The moderating role of psychological empowerment. Journal of Organizational Behavior, 31(4), 609-623. doi:10.1002/job.650

Podsakoff, P. M., \& Organ, D. W. J. J. o. m. (1986). Self-reports in organizational research: Problems and prospects. 12(4), 531-544.

Preacher, K. J., \& Hayes, A. F. (2004). SPSS and SAS procedures for estimating indirect effects in simple mediation models. 36(4), 717-731.

Preacher, K. J., \& Hayes, A. F. (2008). Asymptotic and resampling strategies for assessing and comparing indirect effects in multiple mediator models. 40(3), 879-891.

Raisch, S., \&Birkinshaw, J. (2008). Organizational Ambidexterity: Antecedents, Outcomes, and Moderators. Journal of Management, 34(3), 375-409. doi:10.1177/0149206308316058

Ribiere, V. M., \& Sitar, A. S. (2003). Critical role of leadership in nurturing a knowledgesupporting culture. Knowledge Management Research \& Practice, 1(1), 39-48.

Ribière, V. M., \& Sitar, A. S. (2017). Critical role of leadership in nurturing a knowledgesupporting culture. Knowledge Management Research \& Practice, 1(1), 39-48. doi:10.1057/palgrave.kmrp.8500004

Robbins, P., \& O'Gorman, C. (2015). Innovating the innovation process: an organisational experiment in global pharma pursuing radical innovation. R\&d Management, 45(1), 76-93. 
Sarin, S., \& McDermott, C. (2003). The effect of team leader characteristics on learning, knowledge application, and performance of cross-functional new product development teams. Decision sciences, 34(4), 707-739.

Scuotto, V., Santoro, G., Bresciani, S., \& Del Giudice, M. (2017). Shifting intra-and interorganizational innovation processes towards digital business: an empirical analysis of SMEs. Creativity Innovation Management, 26(3), 247-255.

Shamim, S., Cang, S., \& Yu, H. (2017). Impact of knowledge oriented leadership on knowledge management behaviour through employee work attitudes. The International Journal of Human Resource Management, 1-31. doi:10.1080/09585192.2017.1323772

Singh, M., \& Kant, R. (2008). Knowledge management barriers: An interpretive structural modeling approach. 3(2), 141-150.

Singh, S. K. (2008). Role of leadership in knowledge management: a study. Journal of Knowledge Management, 12(4), 3-15. doi:10.1108/13673270810884219

Sisodiya, S. R., Johnson, J. L., \& Grégoire, Y. (2013). Inbound open innovation for enhanced performance: Enablers and opportunities. Industrial Marketing Management, 42(5), 836-849. doi:10.1016/j.indmarman.2013.02.018

Skogstad, A., Einarsen, S., Torsheim, T., Aasland, M. S., \&Hetland, H. (2007). The destructiveness of laissez-faire leadership behavior. Journal of occupational health psychology, 12(1), 80.

Subramaniam, M., \&Youndt, M. A. J. A. o. M. j. (2005). The influence of intellectual capital on the types of innovative capabilities. 48(3), 450-463.

Tranekjer, T. L., \& Knudsen, M. P. (2012). The (unknown) providers to other firms' new product development: what's in it for them? Journal of Product Innovation Management, 29(6), 986-999.

Uhl-Bien, M., Marion, R., \& McKelvey, B. (2007). Complexity Leadership Theory: Shifting leadership from the industrial age to the knowledge era. The Leadership Quarterly, 18(4), 298-318. doi:10.1016/j.leaqua.2007.04.002

Usman, M., \&Vanhaverbeke, W. (2017). How start-ups successfully organize and manage open innovation with large companies. European Journal of Innovation Management, 20(1), 171-186. https://doi.org/10.1108/EJIM-07-2016-0066

Vaccaro, I. G., Jansen, J. J. P., Van Den Bosch, F. A. J., \&Volberda, H. W. (2012). Management Innovation and Leadership: The Moderating Role of Organizational Size. Journal of Management Studies, 49(1), 28-51. doi:10.1111/j.14676486.2010.00976.x

Viitala, R. (2004). Towards knowledge leadership. Leadership \& Organization Development Journal, 25(6), 528-544. doi:10.1108/01437730410556761

Vlasveld, D. P., Fischer, H. R., Swierenga, E., \&Picken, S. (2008). Interaction of SWCNT and PPTA with sulfuric acid - compatibilization of two materials in a common solvent. Journal of Polymer Science Part B: Polymer Physics. Journal of Polymer Science Part B: Polymer Physics, 46(18), 1914-1922.

Wang, C. L., \& Ahmed, P. K. (2007). Dynamic capabilities: A review and research agenda. International Journal of Management Reviews, 9(1), 31-51. doi:10.1111/j.14682370.2007.00201.x 
Wang, T., \&Libaers, D. (2016). Nonmimetic knowledge and innovation performance: Empirical evidence from developing countries. Journal of Product Innovation Management, 33(5), 570-588.

West, J., \& Gallagher, S. (2006). Challenges of open innovation: the paradox of firm investment in open-source software. R \& d Management, 36(3), 319-331.

Wiklund, J., \& Shepherd, D. (2003). Knowledge-based resources, entrepreneurial orientation, and the performance of small and medium-sized businesses. Strategic Management Journal, 24(13), 1307-1314.

Williams, P., \& Sullivan, H. (2011). Lessons in leadership for learning and knowledge management in multi-organisational settings. International Journal of Leadership in Public Services, 7(1), 6-20. doi:10.5042/ijlps.2011.0089

Yahya, S., \& Goh, W. K. (2002). Managing human resources toward achieving knowledge management. Journal of Knowledge Management, 6(5), 457-468. doi:10.1108/13673270210450414

Yang, J.-T. (2007). Knowledge sharing: Investigating appropriate leadership roles and collaborative culture. TourismManagement, 28(2), 530-543. doi:10.1016/j.tourman.2006.08.006

Yayavaram, S., \& Chen, W. R. (2015). Changes in firm knowledge couplings and firm innovation performance: The moderating role of technological complexity. Strategic Management Journal, 36(3), 377-396.

Zahra, S. A., \& George, G. (2002). Absorptive capacity: A review, reconceptualization, and extension. Academy of management review, 27(2), 185-203., 27(2), 185-203.

Žemaitis, E. (2014). Knowledge Management in Open Innovation Paradigm Context: High Tech Sector Perspective. Procedia - Social and Behavioral Sciences, 110, 164-173. doi:10.1016/j.sbspro.2013.12.859

Zollo, M., \& Winter, S. G. (2002). Deliberate Learning and the Evolution of Dynamic Capabilities. Organization Science, 13(3), 339-351. doi:10.1287/orsc.13.3.339.2780 